\title{
Inventory model with Weibull time-dependent demand rate and completely backlogged permissible delay in payments
}

\author{
R.P. Tripathi ${ }^{\mathrm{a}^{*}}$ and H. S. Pandey
}

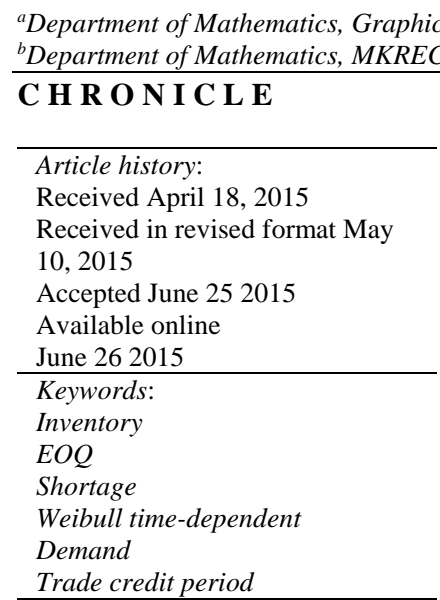

2015 Growing Science Ltd. All rights reserved.

\section{Introduction}

The classical inventory models consider the demand rate to be either constant or time dependent. The classical economic order quantity model was developed in 1915. Thereafter, many models have been developed in the inventory literature considering constant demand. However, in real market, the demand of many products is always, time dependent, price dependent or stock dependent. At present, it can be observed that suppliers often offer a certain fixed credit period to settle the account for stimulating retailer's demand. From the retailer's point of view, during the credit period before payment must be made, he/she can sell the commodities and accumulate the revenue and earn interest. Hence trade credit is an important payment behavior in real business transaction so that the decision of inventory strategies should involve the investment of working capital. In today's business transaction, supplier offers a certain fixed period to settle the account for stimulating his/ her demand. The retailer can accumulate the revenue and earn interest during this credit period. After this period the supplier charges interest on the unpaid balance. Thus a credit period reduces the cost of holding stock indirectly.

* Corresponding author

E-mail address: tripathi_rp0231@rediffmail.com (R.P. Tripathi)

(c) 2015 Growing Science Ltd. All rights reserved. doi: 10.5267/j.uscm.2015.6.003 
However, in practice the supplier offers its customers a permissible delay in payments to attract new customers. To motivate faster payment, stimulate more sales or reduce credit expenses, the supplier also provides the customer a cash discount on the sales.

In inventory management, demand is the major factor. In the study of economic order quantity (EOQ) models, four types of demand are assumed i.e. (i) constant demand (ii) time dependent demand (iii) probabilistic demand and (iv) stock-dependent demand. In classical economic order quantity model the demand rate is assumed to be constant. But in real market situations the demand rate is not always constant but it varies with time. The stock-dependent demand has more relevant at present in the study of inventory models. Mandal and Phaujdar (1989) presented an inventory model for stock-dependent consumption rate. Tripathy and Mishra (2010) discussed an inventory model with time-dependent Weibull demand rate where shortages are allowed. Silver and Meal (1969) were the first to develop the EOQ model for the case of varying demand. Silver and Meal (1973) established an appropriate solution procedure for general case of a deterministic, time dependent demand pattern. Aggarwal et al. (2009) presented an inventory model by considering demand rate as exponentially increasing function of time. Lin and Julian (2012) investigated an inventory model with stock at the beginning and shortages allowed and then partially backlogged. There are many productions in the real world that demand is time-varying or time-dependent. Gupta and Vrat (1986) discussed an inventory model for stockdependent demand rate. Ray and Chaudhuri (1997) investigated a finite time-horizon deterministic economic order quantity inventory model with shortages where the demand rate at any instant depends on the stock-level at that instant. In the past few decades many researchers have developed inventory models by considering time-dependent demand rate. Datta and Pal (1991) developed a finite timehorizon inventory model following the approach to Misra (1979) with linearly time-dependent demand rate allowing shortages and considering the effect of inflation and time value of money. Among the important papers published so for considering the time-dependent and stock-level dependent demand rate, the works of Baker and Urban (1988), Datta and Pal (1990), Urban (2012), Tripathi (2011), Tripathi et al. (2011), Tripathi and Kumar (2011) etc. are worth mentioning.

In most of the models mentioned above shortages does not have significant role to play in the inventory policy. However, some customers are willing to wait for back order and others would turn to buy from other sellers. In many situations shortages are allowed like crisis of raw material, labor strike, lock off, political disturbance, natural calamities, disaster etc. Recently Tripathi (2013) developed an inventory model with shortages and exponential demand rate under trade credits. Researchers such as Wee (1995), Park (1982), Hollier and Mak (1983), Uthayakumar and Geetha (2009) developed inventory models with partial backorders. Recently, Ouyang and Chang (2013) presented an economic production quantity (EPQ) model with imperfect production process and complete backlogging. Chen et al. (2014) established the retailer's optimal EOQ when the supplier offers conditionally permissible delay in payments linked to order quantity. Goyal and Giri (2003) developed production inventory model with shortages, partially backlogged. Wu (1998) developed economic ordering policy of deteriorating items under delay in payments and allowable shortages. Dye et al. (2007) developed a deterministic inventory model for deteriorating items with price-dependent demand rate with allowable shortages and the unsatisfied demand is partially backlogged at a negative exponential rate with the waiting time. Barron (2009) developed an EPQ type inventory model with planned backorders for determining the economic production quantity for a system that generates imperfect quantity product and all these defectives products are reworked in the same cycle. The inventory policies proposed by Jamal et al. (2004) and Sarker et al. (2008) did not consider planned backorders. Chiu (2003) presented an EPQ inventory model that consider the effects of the reworking of defective products on the lot size with backorders allowed, but his model only considered the linear backorder cost.

On the other hand in deriving the EOQ formula, it is tacitly considered that the supplier must pay for the items as soon as the items are received. In today's business transactions we see more and more that supplier would allow a certain fixed period (called credit period) for settling the amount owed to him 
for the items supplied. Within the fixed period there is no charge given by the customer. After this period interest is charged by seller. Liao (2007) derived a production model for the lot size inventory system with finite production rate taking into consideration of the effect of decay and the condition of permissible delay in payments. Liao (2008) considered the impact of the trade credit policy on the classical EPQ model for an item subject to exponential decays. The extensive use of trade credit has been addressed by Goyal (1985) who developed an EOQ model under the condition of permissible delay in payments. Chung (1998) developed an alternative approach to the problem. Aggarwal and Jaggi (1995) extended Goyal's model to allow for deteriorating item. The valuable models related to delay in payments are Shah (1993), Shinn (1997), Hwang and Shinn (1997), Chiu et al. (1998), Khouja and Mehrez (1996), Sarker et al. (2000) and others.

This paper considers an EOQ model for non-deteriorating items with a Weibull time-dependent demand rate under trade credits with shortage. Mathematical models are also derived under two different conditions i.e. case 1: a credit period less than or equal to the time $\mathrm{T}_{1}$ for settling the account and permissible credit period is greater than $\mathrm{T}_{1}$ for settling the account. $\mathrm{T}_{1}$ is the time in which inventory level becomes zero. Expressions for total cost are also derived for two aforesaid cases. Next, we provide the fundamental assumptions for the proposed model and notations in section 2; a mathematical model is established in section 3. In section 4 optimal solutions is given with some important deductions. In section 5, the numerical examples are provided to illustrate the proposed model and the sensitivity analysis of the optimal solution with respect to parameters is carried out in section 6 . Finally, we draw the conclusions and future in section 7.

\section{Notation and Assumptions}

The following assumptions and notations are used to develop the proposed model:

$s \quad$ per unit shortage cost

$h \quad$ per unit holding cost excluding interest charges

p per unit purchase cost

$K \quad$ ordering cost of inventory per order

$I(t) \quad$ inventory level at time ' $t$ '

Ie $\quad$ interest earned

$I_{r} \quad$ interest charges invested in inventory $I_{r} \geq I_{e}$

$m \quad$ permissible delay in settling the account $0<m<T$

$T \quad$ length of the replenishment cycle

$T_{1} \quad$ time at which inventory level becomes zero, $0 \leq T_{1} \leq T$

$Z\left(T_{1}, T\right) \quad$ average total inventory cost per unit time when permissible delay period is $m$

$Z\left(T_{1,}, T\right)=\left\{\begin{array}{l}Z_{1}\left(T_{1}, T\right), \text { for } T_{1} \geq m \\ Z_{2}\left(T_{1}, T\right), \text { for }, T_{1}<m\end{array}\right.$

The following assumptions are used to develop the proposed model:

(1). Shortages are allowed and completely backlogged

(2). The inventory system involves only one item;

(3). Replenishment occurs instantaneously on ordering i.e. lead time is zero.

(4).The demand rate is time dependent and Weibull (two parameter) distribution function given by $D(t)=\alpha \beta t^{\beta-1} ; \alpha, \beta>0$ 
(5). No payment to the supplier is outstanding at the time of placing an order;

(6). time horizon is infinite and is divided into subintervals of length $T$.

\section{Mathematical Formulation}

The inventory level $I(t)$ at time $t$ generally decreases mainly to meet the demand only .Thus the variation of inventory with respect to time can be described by the following differential equation

$$
\frac{d I(t)}{d t}=-\alpha \beta t^{\beta-1} ; 0 \leq t \leq T
$$

The solution of Eq. (1) with $I\left(T_{1}\right)=0$, is

$$
I(t)=\alpha\left(T_{1}^{\beta}-t^{\beta}\right) \quad ; 0 \leq t \leq T
$$

In the interval $\left(0, T_{1}\right)$, holding cost $H C=h \int_{0}^{T_{1}} I(t) d t=\frac{h \alpha \beta}{\beta+1} T_{1}^{\beta}$

The storage cost $S C$ over the time interval $\left(T_{1}, T\right)$ is

$$
S C=s \int_{T_{1}}^{T}-I(t) d t=s \alpha \beta\left\{\frac{T^{\beta+1}}{\beta(\beta+1)}-\frac{T T_{1}^{\beta}}{\beta}+\frac{T_{1}^{\beta+1}}{(\beta+1)}\right\}
$$

Regarding interest payable and earned, the following two possible cases are based on the values of $T_{1}$ and $m$.

\section{Case 1: $m \leq T_{1}$}

Since the length of period with positive stock is larger than the credit period, the buyer can use the sales revenue to earn interest at an annual rate $I_{e}$ in $\left(0, T_{1}\right)$, The interest earned $E_{1}$ is given by

$$
\mathrm{E}_{1}=p I_{e} \int_{0}^{T_{1}} \alpha \beta t^{\beta-1}\left(T_{1}-t\right) d t=\frac{p I_{e} \alpha}{(\beta+1)} T_{1}^{(\beta+1)}
$$

Beyond the credit period, the unsold stock is assumed to be financed with an annual rate $I_{r}$ and the interest payable $I$ is given by

$$
I=p I_{r} \int_{m}^{T_{1}} \alpha \beta t^{\beta-1}\left(T_{1}-t\right) d t=p I_{r} \alpha \beta\left\{\frac{T_{1}^{\beta+1}}{\beta(\beta+1)}-\frac{T_{1} m^{\beta}}{\beta}+\frac{m^{\beta+1}}{(\beta+1)}\right\}
$$

Thus, the total average cost per unit time is given by

$$
\begin{aligned}
& Z_{1}\left(T_{1}, T\right)=\frac{K+H C+S C+I-E_{1}}{T} \\
& Z_{1}\left(T_{1}, T\right)=\frac{1}{T}\left[K+\frac{\alpha}{\beta+1}\left\{\beta(h+s)+p\left(I_{r}-I_{e}\right)\right\} T_{1}^{\beta+1}+\frac{s \alpha}{\beta+1} T^{\beta+1}-s \alpha T T_{1}^{\beta}-p I_{r} \alpha m^{\beta} T_{1}+\frac{p I_{r} \alpha \beta}{\beta+1} m^{\beta+1}\right]
\end{aligned}
$$

Case 2: $m>T_{1}$

In this case, the buyer pays no interest but earns interest at an annual rate $I e$ during the period $(0, m)$. Interest earned $E_{2}$ is given by

$$
E_{2}=p I_{e} \int_{0}^{T_{1}} \alpha \beta t^{\beta-1}(m-t) d t=p I_{e} \alpha \beta\left(\frac{m}{\beta}-\frac{T_{1}}{\beta+1}\right) T_{1}^{\beta}
$$


The total average cost per unit time is given by $Z_{2}\left(T_{1}, T\right)=\frac{K+H C+S C-E_{2}}{T}$

$$
Z_{2}\left(T_{1}, T\right)=\frac{1}{T}\left[K+\frac{h \alpha \beta}{\beta+1} T_{1}^{\beta+1}-p I_{e} \alpha \beta T_{1}^{\beta}\left(\frac{m}{\beta}-\frac{T_{1}}{\beta+1}\right)+\frac{s \alpha}{\beta+1}\left\{T^{\beta+1}-(\beta+1) T T_{1}^{\beta}+\beta T_{1}^{\beta+1}\right\}\right]
$$

\section{Determination of Optimal Solution}

Differentiating partially of Eq. (7) two times with respect to $T_{1}$ and $T$ respectively yields,

$$
\begin{aligned}
& \frac{\partial Z_{1}\left(T_{1}, T\right)}{\partial T_{1}}=\frac{1}{T}\left[\alpha\left\{h \beta+s \beta+p\left(I_{r}-I_{e}\right)\right\} T_{1}^{\beta}-s \alpha \beta T T_{1}^{\beta-1}-p I_{r} \alpha m^{\beta}\right] \\
& \frac{\partial^{2} Z_{1}\left(T_{1}, T\right)}{\partial T_{1}^{2}}=\frac{T_{1}^{\beta-1}}{T}\left[\alpha \beta\left\{h \beta+p\left(I_{r}-I_{e}\right)\right\}+s \alpha \beta\left\{\beta+(1-\beta) \frac{T}{T_{1}}\right\}\right]>0 \\
& \frac{\partial Z_{1}\left(T_{1}, T\right)}{\partial T}=-\frac{1}{T^{2}}\left[K+\frac{\alpha}{\beta+1}\left\{h \beta+s \beta+p\left(I_{r}-I_{e}\right)\right\} T_{1}^{\beta+1}-\frac{s \alpha \beta}{\beta+1} T^{\beta+1}-p I_{r} \alpha T_{1} m^{\beta}+\frac{p I_{r} \alpha \beta}{\beta+1} m^{\beta+1}\right] \\
& \frac{\partial^{2} Z_{1}\left(T_{1}, T\right)}{\partial T^{2}}=\frac{2}{T^{3}}\left[K+\frac{\alpha}{\beta+1}\left\{h \beta+s \beta+p\left(I_{r}-I_{e}\right)\right\} T_{1}^{\beta+1}+p I_{r} \alpha m^{\beta+1}\left(\frac{\beta}{\beta+1}-\frac{T_{1}}{m}\right)+\frac{s \alpha \beta(\beta-1)}{2(\beta+1)} T^{\beta+1}\right]>0
\end{aligned}
$$

$\left(\frac{\partial^{2} Z_{1}\left(T_{1}, T\right)}{\partial T_{1}^{2}}\right)\left(\frac{\partial^{2} Z_{1}\left(T_{1}, T\right)}{\partial T^{2}}\right)-\left(\frac{\partial^{2} Z_{1}\left(T_{1}, T\right)}{\partial T \partial T_{1}}\right)^{2}>0$, and $\frac{\partial^{2} Z_{1}\left(T_{1}, T\right)}{\partial T_{1}^{2}}>0$ and $\frac{\partial^{2} Z_{1}\left(T_{1}, T\right)}{\partial T^{2}}>0$, the optimal values of $T_{1}=T_{1} *$ and $T=T^{*}$ are minimum. Solving $\frac{\partial Z_{1}\left(T_{1}, T\right)}{\partial T_{1}}=0$ and $\frac{\partial Z_{1}\left(T_{1}, T\right)}{\partial T}=0$ yields,

$$
\alpha\left\{h \beta+s \beta+p\left(I_{r}-I_{e}\right)\right\} T_{1}^{\beta}-s \alpha \beta T T_{1}^{\beta-1}-p I_{r} \alpha m^{\beta}=0 .
$$

and

$$
T^{*}=\left[\frac{(\beta+1)}{s \alpha \beta} K+\frac{T_{1}^{\beta+1}}{s \beta}\left\{h \beta+s \beta+p\left(I_{r}-I_{e}\right)\right\}+\frac{p I_{r}(\beta+1) m^{\beta+1}}{s \beta}\left(\frac{\beta}{\beta+1}-\frac{T_{1}}{m}\right)\right]^{1 /(\beta+1)}
$$

For case 2 differentiating Eq. (9) with respect to $T_{1}$ and $T$ two times respectively yields,

$$
\begin{aligned}
& \frac{\partial Z_{2}\left(T, T_{1}\right)}{\partial T_{1}}=\frac{\alpha \beta T_{1}^{\beta-1}}{T}\left\{\left(h+s+p I_{e}\right) T_{1}-\left(s T+p I_{e} m\right)\right\} \\
& \frac{\partial^{2} Z_{2}\left(T, T_{1}\right)}{\partial T_{1}^{2}}=\frac{\alpha \beta T_{1}^{\beta-2}}{T}\left[\left(h+s+p I_{e}\right) \beta T_{1}+(1-\beta)\left(s T+p I_{e} m\right)\right] \\
& \frac{\partial Z_{2}\left(T, T_{1}\right)}{\partial T}=-\frac{1}{T^{2}}\left\{K+\frac{\alpha \beta(h+s)}{\beta+1} T_{1}^{\beta+1}-\frac{s \alpha \beta}{\beta+1} T^{\beta+1}+\alpha p I_{e}\left(\frac{\beta}{\beta+1}-\frac{m}{T_{1}}\right) T_{1}^{\beta+1}\right\} \\
& \frac{\partial^{2} Z_{2}\left(T, T_{1}\right)}{\partial T^{2}}=\frac{2}{T^{3}}\left\{K+\frac{\alpha \beta(h+s)}{\beta+1} T_{1}^{\beta+1}+\frac{s \alpha \beta(\beta-1)}{2(\beta+1)} T^{\beta+1}+\alpha p I_{e}\left(\frac{\beta}{\beta+1}-\frac{m}{T_{1}}\right) T_{1}^{\beta+1}\right\}>0 \\
& \frac{\partial^{2} Z_{2}\left(T_{1}, T\right)}{\partial T_{1}^{2}}>0, \quad \frac{\partial^{2} Z_{2}\left(T_{1}, T\right)}{\partial T^{2}}>0, \text { and }\left(\frac{\partial^{2} Z_{2}\left(T_{1}, T\right)}{\partial T_{1}^{2}}\right)\left(\frac{\partial^{2} Z_{2}\left(T_{1}, T\right)}{\partial T^{2}}\right)-\left(\frac{\partial^{2} Z_{2}\left(T_{1}, T\right)}{\partial T \partial T_{1}}\right)^{2}>0
\end{aligned}
$$


The optimal values for $T_{1}=T_{1} *$ and $T=T^{*}$ is minimum. The optimal values are obtained by solving $\frac{\partial Z_{2}\left(T, T_{1}\right)}{\partial T_{1}}=0$ and $\frac{\partial Z_{2}\left(T, T_{1}\right)}{\partial T}=0$, simultaneously, thus

$$
\begin{aligned}
T_{1}^{* *} & =\frac{\left(s T+p I_{e} m\right)}{\left(h+s+p I_{e}\right)} \\
T^{* *} & =\left\{\frac{(\beta+1)}{s \alpha \beta} K+\frac{(h+s)}{s} T_{1}^{\beta+1}+\frac{(\beta+1) p I_{e}}{s \beta}\left(\frac{\beta}{\beta+1}-\frac{m}{T_{1}}\right) T_{1}^{\beta+1}\right\}^{\frac{1}{\beta+1}}
\end{aligned}
$$

The following properties are observed for optimal $T_{1}, Z_{1}$ and $Z_{2}$.

Deduction 1: Optimal $T_{1}$ is an increasing function of $T$.

Proof: Differentiating equation (14) with respect to $T$ we get,

$$
\frac{d T_{1}^{*}}{d T}=\frac{s T_{1}^{*}}{\left\{\beta(h+s)+p\left(I_{r}-I_{e}\right)\right\} T_{1}^{*}+s(1-\beta) T}>0
$$

as $T_{1}^{*}$ and $T$ are both positive and $\mathrm{I}_{\mathrm{r}} \geq \mathrm{I}$. Also differentiating Eq. (20) with respect to $T$, we get,

$$
\frac{d T_{1}^{* *}}{d T}=\frac{s}{h+s+p I_{e}}>0
$$

Hence optimal $T_{1}$ is a non-decreasing function of $T$.

Deduction 2: Optimal $T_{1}$ is an increasing function of $\mathrm{m}$.

Proof: Differentiating Eq. (14) with respect to $m$, we get

$$
\frac{d T_{1}^{*}}{d m}=\frac{p I_{r} m^{\beta-1}}{\left[\left\{\beta(h+s)+p\left(I_{r}-I_{e}\right)\right\} T_{1}^{*}+s(1-\beta) T\right] T_{1}^{*(\beta-2)}}>0 .
$$

As $T_{1} *$ and $m$ are both positive and $I_{r} \geq I_{e}$. Also differentiating Eq. (20) with respect to $m$, we get,

$$
\frac{d T_{1}^{* *}}{d m}=\frac{p I_{e}}{h+s+p I_{e}}>0
$$

Hence optimal $T_{1}$ is a non-decreasing function of $m$.

Deduction 3: $Z_{1}(T)$ is convex function of $T$.

Proof: Substituting $T_{1} *$ from Eq. (14) to Eq. (7) we get

$$
Z_{1}(T)=\frac{1}{T}\left[K+\frac{\alpha}{\beta+1}\left\{\beta(h+s) p\left(I_{r}-I_{e}\right)\right\} T_{1}^{* \beta+1}+\frac{s \alpha}{\beta+1} T^{\beta+1}-s \alpha T T_{1}^{* \beta}-p I_{r} \alpha m^{\beta} T_{1}^{*}+\frac{p I_{r} \alpha \beta}{\beta+1} m^{\beta+1}\right]
$$

Differentiating Eq. (26) partially with respect to $T$, we get 


$$
\frac{\partial Z_{1}(T)}{\partial T}=-\frac{N}{T^{2}}+\frac{1}{T} \frac{d N}{d T},
$$

where $N$ is the numerator of Eq. (26), for extreme values

$$
\frac{\partial Z_{1}(T)}{\partial T}=0 \text { gives } N=T \frac{d N}{d T},
$$

also

$$
\frac{\partial^{2} Z_{1}(T)}{\partial T^{2}}=\frac{1}{T} \frac{d^{2} N}{d T^{2}}=s \alpha \beta T^{\beta-2}>0
$$

Hence $Z_{1}(T)$ is convex function of $T$.

Deduction 3: $Z_{2}(T)$ is convex function of $T$.

Proof : Substituting $T_{1}^{* *}$ from Eq. (20) to Eq. (9) we get

$$
Z_{2}\left(T_{1}, T\right)=\frac{1}{T}\left[K+\frac{h \alpha \beta}{\beta+1} T_{1}^{* * \beta+1}-p I_{e} \alpha \beta T_{1}^{* * \beta}\left(\frac{m}{\beta}-\frac{T_{1}^{* *}}{\beta+1}\right)+\frac{s \alpha}{\beta+1}\left\{T^{\beta+1}-(\beta+1) T T_{1}^{* * \beta}+\beta T_{1}^{* * \beta+1}\right\}\right]
$$

Differentiating Eq. (30) partially with respect to $T$, we get

$$
\frac{\partial Z_{2}(T)}{\partial T}=-\frac{N^{*}}{T^{2}}+\frac{1}{T} \frac{d N^{*}}{d T},
$$

where ' $N$ *' is the numerator of Eq. (30), for extreme values

$$
\frac{\partial Z_{2}(T)}{\partial T}=0 \text {, gives } N^{*}=T \frac{d N^{*}}{d T}
$$

also

$$
\frac{\partial^{2} Z_{2}(T)}{\partial T^{2}}=\frac{1}{T} \frac{d^{2} N^{*}}{d T^{2}}=s \alpha \beta T^{\beta-2}>0
$$

Hence $Z_{2}(T)$ is convex function of $T$.

\section{Examples}

Example 1: Let $K=\$ 10.00$ per order, $h=\$ 20.00$ per unit, $p=\$ 100.00$ per unit, $s=\$ 50.00$ per unit, $\alpha$ $=0.2, \beta=0.5, I_{r}=0.2, I_{e}=0.1$, find the optimal values of $T_{1}, T$ and $Z\left(T_{1}, T\right)$.

Solution1: Case 1: $m \leq T_{1}$

We take m0.08333 year, solving the Eqs. (14) and Eq. (15) simultaneously for $T_{1}$, and $T$, we obtain $T_{1}$ * $=1.12921$ year and $T^{*}=1.78717$ years

Putting the values in Eq. (7) we get optimal value of $Z_{1}\left(T_{1}{ }^{*}, T^{*}\right)=\$ 7.19826 /$ unit time 
Optimality conditions holds as $\frac{\partial^{2} Z_{1}\left(T_{1}, T\right)}{\partial T_{1}^{2}} \frac{\partial^{2} Z_{2}\left(T_{1}, T\right)}{\partial T^{2}}-\left(\frac{\partial^{2} Z_{1}\left(T_{1}, T\right)}{\partial T_{1} \partial T}\right)^{2}=14.81>0$ and $\frac{\partial^{2} Z_{1}\left(T_{1}, T\right)}{\partial T_{1}^{2}}=$ $4.4529>0$ on the given values.

Case 2: $T_{1}<m$

We take $m=1.25$ years, solving the Eqs. (20) and Eq. (21) simultaneously for $T_{1}, T$, we obtain $T_{1} * *$ $=1.19116$ year and $T^{* *}=1.65585$ years.

The optimal value of total cost is $Z_{2}\left(T_{1}^{* *}, T^{* *}\right)=\$ 6.2433$ per unit time.

Optimality conditions holds as $\frac{\partial^{2} Z_{2}\left(T_{1}, T\right)}{\partial T_{1}^{2}} \frac{\partial^{2} Z_{2}\left(T_{1}, T\right)}{\partial T^{2}}-\left(\frac{\partial^{2} Z_{2}\left(T_{1}, T\right)}{\partial T_{1} \partial T}\right)^{2}=16.58341>0$ and $\frac{\partial^{2} Z_{2}\left(T_{1}, T\right)}{\partial T_{1}^{2}}=$ $4.4267>0$ on the given values. Also the variation of optimal solution for different values of $m$ is given in Table 1(a) and Table 1(b) in section 6 .

Example 2: Taking the values of the all parameters the same as the ones given in Example 1 except $\beta$ $=1.5$, the variation of optimal solution for different values of $m$ is given in Table 2(a) and Table 2(b) in section 6.

\section{Sensitivity Analysis}

The variation of optimal solution for different values of $m$ is shown in Tables 1(a), 1(b), 2(a), and 2(b), for $\beta=0.5$ and $\beta=1.5$ respectively. Also the variation of optimal solution for different values of ' $h$ ' and 's' is shown in Tables 3(a), and 3(b). Fig. 1, Fig. 2 and Fig. 3 show the behavior of total cost function with respect to $T_{1}$ and $T$. The graphs are drawn with the help of Mathematica7.0 software. Note: $m, T_{1}$, and $T$ are taken in years in Table 1 to Table 5 as follows.

Table 1(a)

Example 1, case-1, $\beta=1.5$

\begin{tabular}{cccc}
\hline$m$ & $T_{1}^{*}$ & $T^{*}$ & $Z_{1}\left(T_{1}^{*}, T^{*}\right)($ in $\$)$ \\
\hline 0.08333 & 1.12921 & 1.78717 & 7.19826 \\
0.16667 & 1.19200 & 1.78902 & 6.91605 \\
0.25000 & 1.24378 & 1.79270 & 6.9975 \\
0.33333 & 1.29026 & 1.79782 & 6.51877 \\
0.41667 & 1.33363 & 1.80419 & 6.36102 \\
\hline
\end{tabular}

\section{Table 1(b)}

Example 1, case-2, $\beta=1.5$

\begin{tabular}{cccc}
\hline$m$ & $T_{1} *$ & $T^{*}$ & $Z_{1}\left(T_{1}{ }^{*} T^{*}\right)($ in $\$)$ \\
\hline 1.25000 & 1.19116 & 1.65585 & 6.24331 \\
1.33333 & 1.19362 & 1.64313 & 6.16600 \\
1.41667 & 1.19602 & 1.63029 & 6.08813 \\
1.50000 & 1.19833 & 1.61733 & 6.00974 \\
1.58333 & 1.20057 & 1.60424 & 5.93080 \\
\hline
\end{tabular}


Table 2(a)

Example 2, case-1, $\beta=1.5$

\begin{tabular}{cccc}
\hline$m$ & $T_{1}^{*}$ & $T^{*}$ & $Z_{1}\left(T_{1}^{*}, T^{*}\right)($ in $\$)$ \\
\hline 0.5000 & 1.82819 & 2.73349 & 11.4358 \\
0.58333 & 1.85141 & 2.75151 & 11.3215 \\
0.66667 & 1.87780 & 2.77337 & 11.2168 \\
0.75000 & 1.90735 & 2.79918 & 11.1242 \\
0.83330 & 1.93997 & 2.82899 & 11.0454 \\
\hline
\end{tabular}

Table 2(b)

Example 2, case- $2, \beta=1.5$

\begin{tabular}{cccc}
\hline$m$ & $T_{1}^{*}$ & $T^{*}$ & $Z_{1}\left(T_{1}^{*}, T^{*}\right)($ in $\$)$ \\
\hline 2.08333 & 2.05254 & 2.86740 & 9.43774 \\
2.16667 & 2.07239 & 2.88249 & 9.31719 \\
2.25000 & 2.09220 & 2.89752 & 9.19501 \\
2.33333 & 2.11198 & 2.91249 & 9.07119 \\
2.41667 & 2.13172 & 2.92741 & 8.94575 \\
\hline
\end{tabular}

Table 3(a)

$\mathrm{m}=0.08333$ year, $\mathrm{s}=\$ 50, \beta=0.5$

\begin{tabular}{cccc}
\hline$m$ & $T_{1}^{*}$ & $T^{*}$ & $Z_{1}\left(T_{1}^{*}, T^{*}\right)($ in $\$)$ \\
\hline 20 & 1.129210 & 1.78717 & 7.19826 \\
30 & 0.991201 & 1.75248 & 7.31956 \\
40 & 0.882194 & 1.72392 & 7.47304 \\
50 & 0.794039 & 1.69991 & 7.64073 \\
60 & 0.721357 & 1.67939 & 7.81271 \\
\hline
\end{tabular}

Table 3(b)

$\mathrm{m}=0.08333$ year, $\mathrm{h}=\$ 20, \beta=0.5$

\begin{tabular}{cccc}
\hline$m$ & $T_{1} *$ & $T^{*}$ & $Z_{1}\left(T_{1}^{*}, T^{*}\right)($ in $\$)$ \\
\hline 50 & 1.129210 & 1.78717 & 7.19826 \\
60 & 1.085220 & 1.60822 & 7.78962 \\
70 & 1.042700 & 1.47009 & 8.33702 \\
80 & 1.002580 & 1.35935 & 8.85215 \\
90 & 0.965143 & 1.26805 & 9.34241 \\
\hline
\end{tabular}

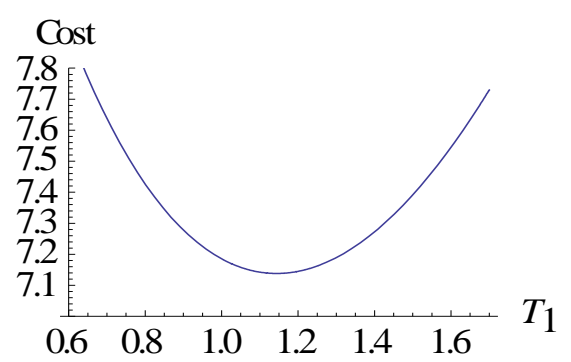

Fig.1. Total cost vs $\mathrm{T} 1$ at fixed $\mathrm{T}=1.81164$
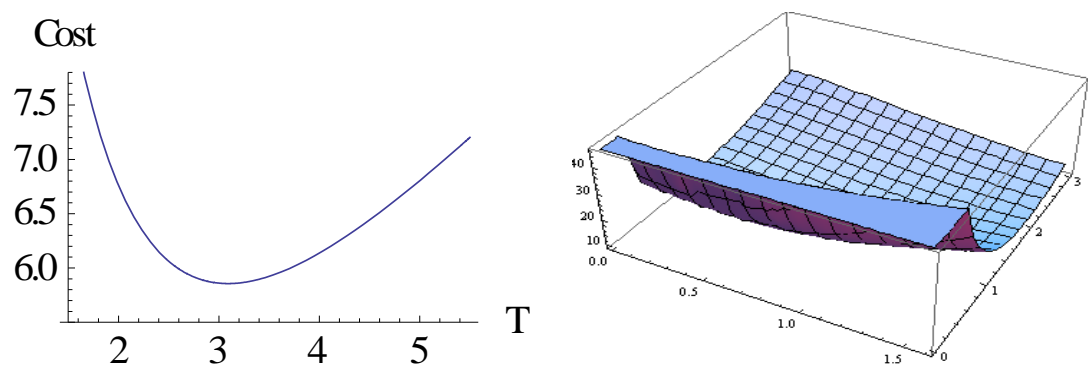

Fig. 3. Total cost vs $\mathrm{T} 1$ and $\mathrm{T}$ $\mathrm{T} 1=1.37498$

We draw the following conclusions from the above Tables and figures.

(1) The numerical results shown in Table 1(a), for case-1, indicate that $T_{1} *$ is an increasing function of $m$ as well as $T$ With an increase in permissible period ' $m$ ' total cost $Z\left(T_{1}, T\right)$ decreases significantly. 
(2) The numerical results shown in Table 1(b), for case-1, indicate that the higher values of $m$ allow the higher values of $T_{1}$ simultaneously the lower values of $T$, Total cost $Z\left(T_{1}, T\right)$ decreases as ' $m$ ' increases.

(3) The numerical results shown in Table 2(a) and Table 2(b) for case-1 and case-2 indicate that $T_{1}$ and $T$ are both directly proportional to permissible period ' $m$ '. Total cost $Z\left(T_{1}, T\right)$ is inversely proportional to ' $m$ '.

(4) In Table 3(a), it is seen that the higher values of holding cost ' $h$ ' results the higher values in total cost $\mathrm{Z}\left(\mathrm{T}_{1}, \mathrm{~T}\right)$ and the lower values in $T_{1}$ and $T$.

(5) Fig. 1 and Fig. 2 visualize that total cost function $Z\left(T_{1}, T\right)$ is convex with respect to $T_{1}$ and $T$ individually.

(6) Graphics shown in Fig. 2 is data visualization of $T_{1}$, $T$ verses total $\operatorname{cost} Z\left(T_{1}, T\right)$ indicates that $Z\left(T_{1}, T\right)$ is convex in $T_{1}$ and $T$ simultaneously.

\section{Conclusion and future Research}

The present model has been based on a Weibull time dependent demand rate. While dealing with time varying demand pattern, the researcher usually takes the demand rate to be an exponential of the form $\mathrm{R}(\mathrm{t})=a e^{b t}, a>0,0<b<1$ or $b<0$, which is rarely seen to occur for any product. Most of the authors considered constant demand or stock dependent demand. We developed inventory model for nondeteriorating and Weibull time dependent demand rate for finding optimal order policy when the supplier provides a trade credits. We have shown that Total coat function is convex with respect to $T_{1}$ and $T$. The figures 1 and 2 show the validity of convexity of total cost function with respect to $T_{1}$ and $T$. Numerical examples and sensitivity analysis are given to validate the model. From the sensitivity analysis it is clear that the variations are quite sensitive with respect to variation of parameters.

The proposed model can be extended in several ways. For instance; we could consider the demand rate as a function of selling price, product quantity and others. Finally, we could generalize the model to allow for shortages and quantity discount, freight charges and others.

\section{References}

Aggarwal, S.P., \& Jaggi, C.K. (1995). Ordering policies of deteriorating items under permissible delay in payments. Journal of Operational Research Society, 46, 658-662.

Agarwal, R., Rajput, D., \& Varshney, N.K. (2009). Integrated inventory system with the effect of inflation and credit period. International Journal of Applied Engineering Research, 4(11), 23372348.

Baker, R.C., \& Urban, T.L. (1988). A deterministic inventory system with inventory- level dependent demand rate. Journal of operational Research Society, 39, 823-831.

Barron, L.E.C. (2009). Economic production quantity with rework process at a single- stage manufacturing system with planned backorders. Computers and Industrial Engineering, 57, 11051113.

Chen, S. C., Cárdenas-Barrón, L. E., \& Teng, J. T. (2014). Retailer’s economic order quantity when the supplier offers conditionally permissible delay in payments link to order quantity. International Journal of Production Economics,155, 284-291.

Chiu, Y.P. (2003). Determining the optimal lot size for the finite production model with random defective rate, the rework process and backlogging. Engineering Optimization, 35(4), 427-437.

Chung, K.J. (1998). A theorem on the determination of economic order quantity under condition of permissible delay in payments. Computers and Operations Research,25, 49-52. 
Chu, P., Chung, K.J., \& Lan, S.P. (1998). Economic order quantity of deteriorating items under permissible delay in payments. Computer and Operational Research, 25, 817-824.

Datta, T.K., \& Pal, A.K. (1990). A note on an inventory model with inventory level with inventorylevel- dependent demand rate. Journal of Operational Research Society, 41(10), 971-975.

Datta, T.K., \& Pal, A.K. (1991). Effects of inflation and time- value of money on an inventory model with linear time - dependent demand rate and shortages. European Journal of Operational Research, 52, 1-8.

Dye, C.Y., Hsieh,T.P., \& Ouyang, L.Y. (2007). Determining optimal selling price and lot size with a varying rate of deterioration and exponential partial backlogging. Tamsui Oxford Journal of Mathematical Sciences, 181, 668-678.

Goyal, S.K. (1985). Economic order quantity under conditions of permissible delay im payments. Journal of Operational Research Society, 36, 335-338.

Goyal, S.K., \& Giri, B.C. (2003). The production inventory problem of a product with time varying demand, production and deterioration rate. European Journal of Operational Research, 147, 549557.

Gupta, R., \& Vrat, P. (1986). Inventory model for stock - dependent consumption rate. Opsearch, 23(1), 19-24.

Hollier, R.H., \& Mak, K.L. (1983). Inventory replenishment policies for deteriorating items in a declining market. International Journal of Production Economics, 21, 813-826.

Hwang, H., \& Shinn, S.W. (1997). Retailer's pricing and lot sizing policy for exponentially deteriorating products under the condition of permissible delay in payments. Computer and Operational Research, 24, 539-547.

Jamal, A.M.M., Sarker, B.R., \& Mandal,S. (2004). Optimal manufacturing batch size with rework process at single- stage production system. Computers and Industrial Engineering, 47(1), 77-89.

Khouja, M., \& Mehrez, A. (1996). Optimal inventory policy under different supplier credits. Journal of Manufacturing System, 15, 334-339.

Liao, J.J. (2007). On an EPQ model for deteriorating items under permissible delay in payments. Applied Mathematical Modelling, 31, 393-403.

Liao. J.J. (2008). An EOQ model with non-instantaneous receipt and exponentially deteriorating items under two- level trade credits. International Journal of Production Economics, 113, 853-861.

Lin, J., \& Julian, H.C. (2012). A demand independent inventory control. Yugoslav Journal of Operations Research, 22, 1-7.

Mandal, B.N., \& Phaujdar, S. (1989). An inventory model for deteriorating items and stock- dependent consumption rate. Journal of operational Research Society, 40(5), 483 -488.

Misra, R.B. (1979). A note on optimal inventory management under inflation. Noval Research Logistics, 26, 161-165.

Ouyang, L.Y., \& Chang, C.T. (2013).Optimal production lot with imperfect production process under permissible delay in payments and complete backlogging. International Journal of Production Economics, 144(2), 610-617.

Park, K.S. (1982). Inventory models with partial backorders. International Journal of System Science, 13, 1313-1317.

Ray, J., \& Chaudhuri, K.S. (1997). An EOQ model with stock- dependent demand, shortages, inflation and time- discounting. International Journal of Production Economics , 53, 171-180.

Sarker, B.R., Jamal, A.M.M., \& Wang, S. (2000). Optimal payment time under permissible delay in payment for product with deterioration. Production Planning and Control, 11, 380-390.

Sarker, B.R., Jamal, A.M.M., \& Mandal, S. (2008). Optimal batch sizing in a multi-stage production system with rework consideration. European Journal of Operational Research, 184(3), 915-929.

Shah, N.H. (1993). A lot size model for exponentially decaying inventory when delay in payments is permissible. Cah,du,CERO, 35,115-123.

Shinn, S.W. (1997). Determining optimal retail price and lot size under delay items supplier credit. Computer and Industrial Engineering, 33, 717-720. 
Silver, E.A., \& Meal, H.C. (1969). A simple modification of the EOQ model for the case of a varying demand rate. Production and Inventory Management, 10, 52-65.

Silver, E.A., \& Meal, H.C. (1973). A heuristic for selecting lot size quantities for the case of a deterministic time - varying demand rate and discrete opportunities of replenishment. Journal of operational Research Society, 14, $64-74$.

Tripathy, C. K., \& Mishra, U. (2010). An inventory model for Weibull Time- dependent demand rate with completely backlogged shortages. International Mathematical Forum, 5(54). 2675-2687.

Tripathi, R.P. (2011). EOQ model with time- dependent demand rate and time- dependent holding cost function. International Journal of Operations Research and Information System, 2(3), 79-92.

Tripathi, R.P., Misra, S.S., \& Shukla, H.S. (2011). A cash flow oriented EOQ model of deteriorating items with time- dependent demand rate under permissible delay in payments. International Journal of Business and Information Technology, 1(2), 153-158.

Tripathi R.P. and Kumar ,M. (2011). Credit financing in economic ordering policies of timedependent. International Journal of Business, Management and Social Sciences, 2(3), 75-84

Tripathi, R.P. (2013). An inventory model with shortages and exponential demand rate under permissible delay in payments. International Journal of Management Science and Engineering Management, 7(2), 134-139.

Urban, T.L. (2012). An extension of inventory models incorporating financing agreements with both suppliers and customers. Applied Mathematical Modelling, 36, 6323-6330.

Uthayakumar, R., \& Geetha, K.V. (2009). A replenishment policy for non- instantaneous deteriorating inventory system with partial backlogging. Tamsui Oxford Journal of Mathematical Sciences, 25, 313-332.

Wee, H.M. (1995). A deterministic lot-size inventory model for deteriorating items with shortages and declining Market. Computers and Operations Research, 22, 345-356.

Wu, K.S. (1998). An ordering policy for items with weibull distribution deterioration under permissible delay in payments. Tamsui Oxford Journal of Mathematical Sciences, 14, 39-54. 